\title{
Laryngocele - A Case Report and Review of Literature
}

\author{
M. Vishnu Vardhan Reddy · C. Ramakrishna - Manish Gupta \\ A. Shobhan Babu · T. Shankar · Ranveer Singh · S. Satish Kumar
}

\begin{abstract}
This is case report of 35-year old male patient presented with hoarseness and swelling on left side of neck. The swelling was noticed by the patient for 8 months. It has been diagnosed clinically and radiologically as a combined laryngocele. The laryngocele has been successfully excised using and combined approach i.e., external and endoscopic methods. This case has been reported for its rarity at this age.
\end{abstract}

Keywords Laryngocele $\cdot$ lateral thyrotomy approach • MRI Neck

\footnotetext{
M. V. V. Reddy $(\bowtie) \cdot$ C. Ramakrishna $・$ M. Gupta • A. S. Babu • T. Shankar $\cdot$ R. Singh $\cdot$ S. S. Kumar Osmania Medical College

Govt. ENT Hospital

Koti, Hyderabad

e-mail: vishnumreddy@yahoo.co.in
}

\section{Introduction}

Larry, a surgeon in Napoleon army, first described laryngocele in 1829. It was in Egypt that he first observed this type of goiter. It was observed mostly in blind individual who were employed by temple authorities to blow the trumpet for long hours. The blowing produced large air packets under the jaws.

Laryngocele is a very rare condition. Sometimes it presents as neck abscess or may be mistaken with any other cystic lesion in neck. Knowledge about it shall help the physician in making the correct diagnosis.

\section{Case Report}

A 35-year old male driver on occupation, known smoker presented to ENT OPD with complaints of hoarseness of voice and swelling over left side of neck for 8 months, insidious in onset and gradually progressive. Swelling increased in size on coughing and straining and decreased in size on compression. There is no history of chronic cough, straining at stools, stridor, fever or loss of weight, trauma, and difficulty in swallowing or breathing.

On clinical examination, a single swelling about 7x6 $\mathrm{cm}$ present in front of left sternocliedomastoid at junction of anterior $1 / 3$ and middle $1 / 3$ and $3 \mathrm{~cm}$ below angle of the mandible, not moving with deglutition or protrusion of the tongue, it increased in size on coughing and performing valsalva manoeuvre (Fig. 1). It is soft, cystic, non tender, fluctuation is positive, reducing in size with manual compression. IDL showed fullness in left vallecular region. DL confirmed the same. On U/S of neck, small sub cutaneous swelling is seen just inferior to submandibular gland on left side filled air and increased size on blowing. MRI of neck showed well defined bilobed air filled sac on left side of neck, $5.1 \times 2.8 \mathrm{~cm}$ in size (Fig. 2). The sac is seen to communicate with the larynx and is causing compression over infraglottic portion of larynx. Epiglottis is displaced to right side.

\section{Operative procedure}

Elective tracheostomy was done under local anesthesia and portex tube placed. General anesthesia is continued through 


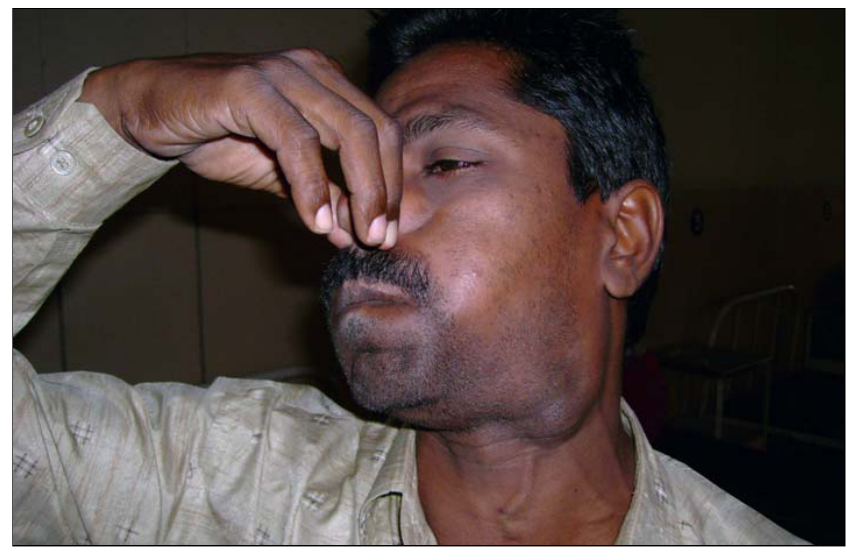

Fig. 1 Laryngocele increasing in size during valsalva manoeuvre.

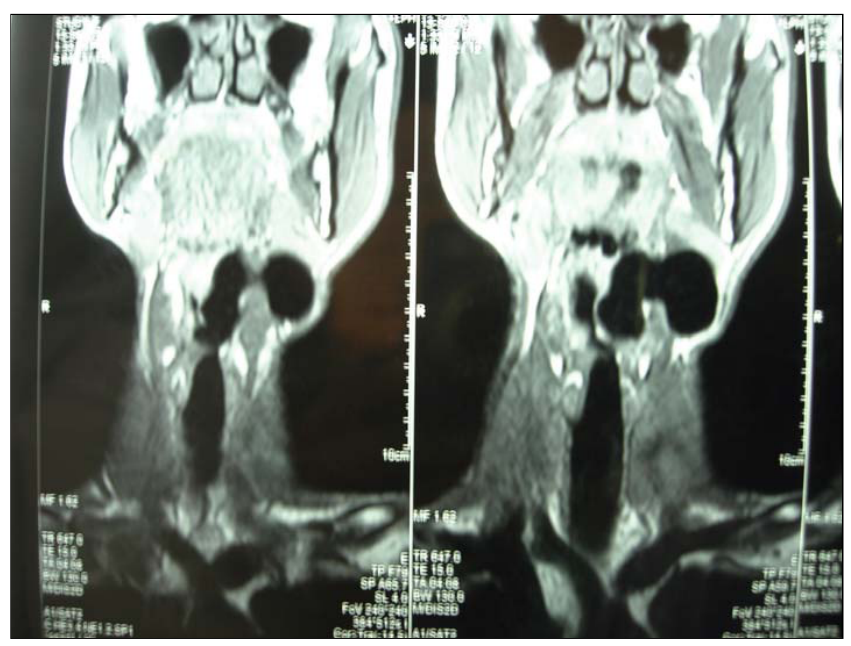

Fig. 2 MRI Neck showing mixed type laryngocele containing external and internal components.

portex tube. Collar incision placed over the swelling on left side of the neck.Subplatysmal flap elevated and dissection done till the external part of laryngocele is identified clearly. The laryngocele neck is found to be continuing in to larynx through thyrohyoid membrane. Using Macintosh laryngoscope internal part of laryngocele identified. Upper $1 \backslash 3$ of thyroid ala removed (lateral thyrotomy approach).This facilitated exposure and excision of internal part of laryngocele. Complete excision of laryngocele was confirmed endoscopically. The wound closed in layers and a corrugated rubber drain kept .Recovery was uneventful. Histopathological examination revealed psuedostratified columnar epithelial lining with fibrocollagenous tissue and numerous blood vessels. There was no evidence of neoplasia.

\section{Discussion}

Laryngocele is an abnormal dilatation or herniation of saccule that communicates with lumen of larynx and it is air filled lined by pseudo stratified columnar epithelium. If this 㮣 Springer

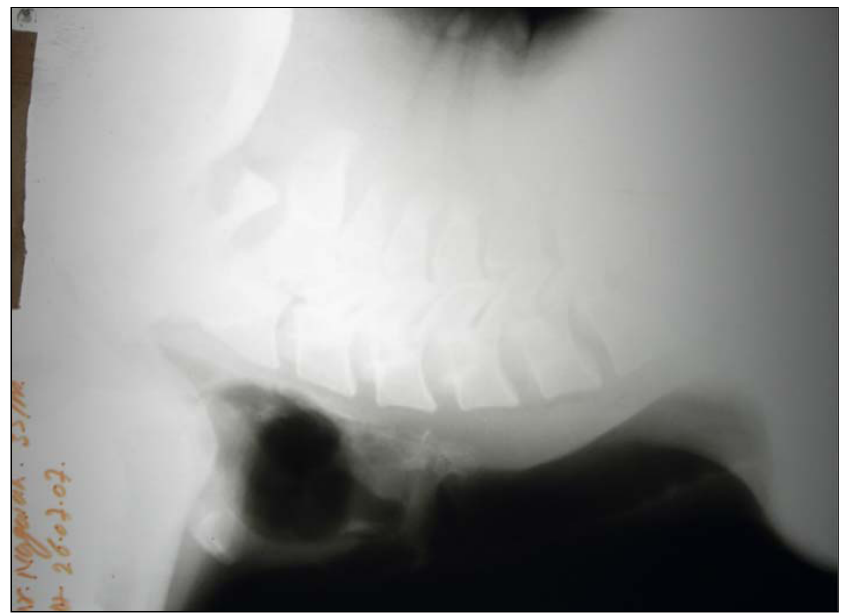

Fig. 3 Plain X- Ray showing laryngocele.

herniation of saccule extends to medial and superior to thyroid cartilage and pierces the thyrohyoid membrane at the entrance of superior laryngeal nerve and vessels, then it is called external laryngocele.If herniation of saccule does not pierce the membrane, it remains with in larynx to form an internal laryngocele.If both are present then it is called combined laryngocele.A laryngocele may become infected and it is then called a laryngopyocele.Stell and Maran in a review of 139 cases showed that peak age incidence is in sixth decade and 2 out of 3 laryngoceles are unilateral and they may be combined, external or internal with roughly equal frequency. About $8 \%$ get infected and present as pyocele[1].

Etiology is unclear as there is no evidence to show that hobbies involving blowing or jobs such as trumpet playing or glass blowing cause laryngocele. Laryngocele in humans represent atavistic remnants of air sacs of lower animals.Blowing increase intralaryngeal pressure and bring otherwise symptomless laryngocele to manifest [1]. In another review of etiology it was suggested that local laryngeal pathologies are major factors in pathogenesis of disease [2]. Laryngeal cancer is sometimes associated with laryngocele. The pathogenesis of laryngoceles appears to be related to factors altering the mechanics of laryngeal ventricle to a chronically elevated intralaryngeal pressure. Ball valve effect appears to be a factor for saccular dilatation in some cases. In other instances the association between laryngocele and cancer is probably coincidental [3]. In literature, laryngocele associated with amyloidosis [4], ankylosing spondylitis are reported .It has been reported as an acquired condition, after excision of submandibular gland for chronic sialadinitis and salivary calculus [5] and tracheostomy [6].

The symptoms and signs depend upon type of laryngocele. It may be asymptomatic at onset and produce symptoms only as it enlarges. The internal laryngocele presents as hoarseness due to interference with vocal cords, dyspnoea due to encroachment on the laryngeal space, reflex cough and sensation of foreign body in throat due to irritation. Indirect and direct laryngoscope shows smooth swellings of supra glottis. 
The external laryngocele gives few symptoms manifests primarily by objective signs. It presents as swelling in neck at level of hyoid bone anterior to sternocleidomastoid muscle. Swelling will increase during Valsalva maneuver \& become smaller on palpation \& pressure.

The mixed type produces both hoarseness \& swelling. The pathogenic feature for mixed type laryngocele is sudden onset stridor; following compression of external compartment. This is due to passage of air from external to internal sac. It is dangerous complication because internal component of laryngocele suddenly becomes larger and may cause acute upper respiratory obstruction and lead to death. Mucopurulent material from laryngopyocele may spill into trachea and may cause death [7].

The diagnosis may be established by plain radiographs, but more accurate information is gained by CT or MRI scan. MRI scan helps defining the spatial relationship between laryngocele and laryngeal structures and extra laryngeal soft tissues, in differentiating laryngoceles from other cystic formation and identifying coexistent of laryngeal cancer. Main aim of surgery is excision of the sac as this would prevent enlargement and eventual obstruction of larynx due to extrinsic compression.

External laryngocele are removed by an external approach (transcervical) with or without tracheostomy. Access may be improved by performing lateral thyrotomy with excision of upper third of thyroid cartilage [8] .The base of laryngocele is ligated, if possible without entering the laryngeal lumen. Endoscopic assisted $\mathrm{CO}_{2}$ laser excision is an alternative to external approach [9].

Simple endoscopic uncapping is done for internal laryngocele and saccular cysts. Other methods are endoscopic $\mathrm{CO}_{2}$ laser vestibulectomy [10] and endoscopic microsurgical excision [11].
In combined cases combined approach using both endoscopic as well as external approach may be used at the same time. We believe that advances in the application of lasers in microlaryngeal surgery will alter the traditional management of all types of laryngoceles.

\section{References}

1. Stell PM, Maran AGD (1975) Laryngocele. J Laryngo Otol 89:915-924

2. Amin M, Maran AG (1988) The aetiology of laryngocele. Clin otolaryngol Allied Sci 13(4):267-272

3. Canalis RF (1976) Observations on the Simaltaneous occurrence of laryngocele and Cancer. J otolaryngol 5(3): 207-212

4. Ayden O, Unstundag E, Iseri M, et al (1999) Larygeal amyloidosis with laryngocele. J Laryngol oto 113(4):278-281

5. Abu-Khalat M, Tarawneh M (1981) Laryngocele: an acquired condition. J Laryngol otol 95(4):425-429

6. Tahwinder Upile (2006) Laryngocele: a rare complication of surgical tracheostomy. BMC Surgery 6:14

7. Bentyman W, Haidak GL and Taylor M (1959) Laryngocele: a report of fatal case. New England J. Med 260:1025-1027

8. Thome R, Thome DC, De La cortina RA (2000) Laryngosocpe: Lateral thyrotomy approach on paraglotic space for laryngocele resection. 110(3 pt 1):447-450

9. Martinez Devesa P. Ghufoor K, Lloyd S, Howard D (2002) Endoscopic $\mathrm{CO}_{2}$ laser management of laryngocele Laryngoscope 112 (8 pt 1):1426-1430

10. Szwarc BJ, Kashima HK (1997) Endoscopic management of Combined laryngocele. Ann Otol Rhinal Laryngol 106(7 pt 1):556-559

11. Dursun G, Ozgursoy OB, Beton S, Batikhan H (2007) Current Diagnosis and treatment of laryngocele in adults. Otolaryngol Head Neck Surgery 136(2):211-215 